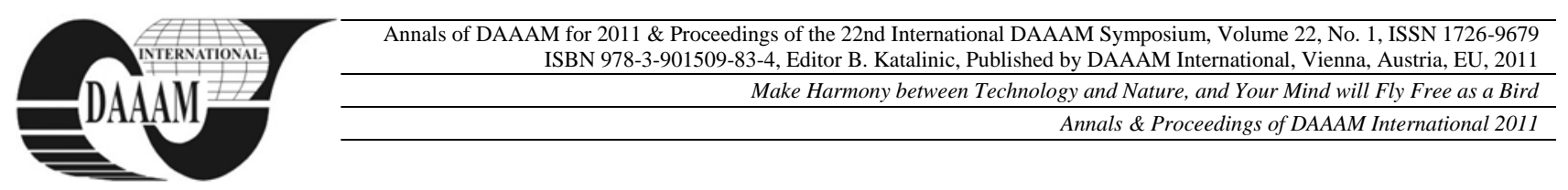

\title{
THE INTERNET AND INTEGRATED MARKETING COMMUNICATIONS
}

\author{
MARKOVA, P[etra]; PRAJOVA, V[anessa] \& SALGOVICOVA, J[armila]
}

\begin{abstract}
One popular conception of marketing is that it primarily involves sales. Other perspectives view marketing as consisting of advertising or retailing activities. For some of you, market research, pricing, or product planning may come to mind. While all these activities are part of marketing, it encompasses more than just these individual elements. The Internet is a worldwide means of exchanging information and communicating through a series of interconnected computers. While the most popular component of the Internet is the World Wide Web (www). For marketers, a number of these features offer potential, but it is the Web that has developed as the commercial component (Hughes G.\&Fill Ch., 2006). Thus, we have stayed away from the technical jargon, concentrating primarily on marketing communications terms.
\end{abstract}

Key words: internet, marketing, integrated marketing communications, public relations, direct marketing

\section{INTRODUCTION}

Marketing communication is an ever-changing field. New theories, new techniques, cultural changes and technological advances all combine to create a dynamic environment within which marketers try to ensure that their messages get through to their target audiences. For most non-marketers, marketing communications is the whole of marketing. Like an iceberg. Only the tip is visible, the general public do not see product development, pricing strategies, or distribution in the same way as they see communications. Marketers themselves are often constrained by their employers into being primarily communicators, and the ability to generate well-turned advertising phrases or create arresting TV advertising is among the most prized of talents in professional marketing. Communication is one of the most human of activities. The exchange of thoughts which characterises communication is carried out by conversation, by the written word, and by pictures. Communication has been defined as a transactional process between two or more parties whereby meaning is exchanged through the intentional use of symbols. The key elements here are that the communication is intentional, it is a transaction, and it is symbolic. Since human beings are not telepathic, all communication requires that the original concepts be translated into symbols which convey the required meaning.

\section{THE INTERNET AND INTEGRATED MARKETING COMMUNICATIONS}

Advertising on the Internet - Like broadcast or print, the Internet is an advertising medium. Companies and organizations working to promote their products and services must consider this medium as they would television, magazines, outdoor, and so on (Hughes \& Fill, 2006).

Banners - The most common form of advertising on the Web is banner ads. Banner ads may be used for creating awareness or recognition or for direct-marketing objectives. Banner ads may take on a variety of forms as well as a number of names such as side panels, skyscrapers, or verticals. Initially banner ads constituted the vast majority of advertising on the Net, but studies indicating their questionable effectiveness have led to a decline in usage. Reports on click-through rates vary, but most studies indicate a less than 1 percent response rate. A few studies have shown an increase in response rates in recent years. These findings may lead to increased use of this method of advertising in the future (Belch \& Belch, 2003).

Sponsorships - Another common form of advertising is sponsorships. There are two types of sponsorships. Regular sponsorships occur when a company pays to sponsor a section of a site. A more involved agreement is the content sponsorship, in which the sponsor not only provides dollars in return for name association but participates in providing the content itself. In some cases, the site is responsible for providing content and having it approved by the sponsor; in other instances, the sponsor may contribute all or part of the content. Due in part to the lack of effectiveness of banner ads, sponsorships have been increasing in popularity (Milton \& Westphal, 2005).

Interstitials - Interstitials are ads that appear on your screen while you are waiting for a site's content to download. Although some advertisers believe that interstitials are irritating and more of a nuisance than a benefit (Belch \& Belch, 2003).

Push Technologies - Push technologies, or webcasting technologies, allow companies to "push" a message to consumers rather than waiting for them to find it. Push technologies dispatch web pages and news updates and may have sound and video geared to specific audiences and even individuals (Belch \& Belch , 2003).

Links - While considered by some as not a type of advertising, links serve many of the same purposes as are served by the types discussed above. For example, a visitor to one site may click on a link that provides additional information and/or related materials at another site. At the bottom of the homepage at women.com are a number of links to magazines. Clicking on one of these takes you to the magazine's site and usually a pop-up for a subscription to the magazine appears. Other forms of advertising, such as ads placed in chat rooms, are also available. Given the limited use of many of these alternatives, we suggest the reader consult additional resources for more information (Larkin, 2003).

\section{PERSONAL SELLING ON THE INTERNET}

The Internet has been both a benefit and a detriment to many of those involved in personal selling - particularly those in the business-to-business market. For some, the Internet has been a threat that might take away job opportunities. Companies have found that they can remain effective - even increase effectiveness - by building a strong Web presence. The high-cost and poor-reach disadvantages of personal selling are allowing these companies to reduce new hires and even cut back on their existing sales forces (Fombrun et al., 2000).

On the positive side, websites have been used quite effectively to enhance and support the selling effort. As noted 
earlier, the Web has become a primary source of information for millions of customers in the consumer and business-tobusiness markets. Visitors to websites can gain volumes of information about a company's products and services. In return, the visitors become a valuable resource for leads that both internal and external salespersons can follow up, and they become part of a prospect database. Not only can potential customers learn about the company's offerings, but the selling organization can serve and qualify prospects more costeffectively (Hughes \& Fill, 2006).

The Web can also be used to stimulate trial. For many companies, personal salespersons can reach only a fraction of the potential customer base. Through trial demonstrations and/or samples offered online, customers can determine if the offering satisfies their needs and if so request a personal sales call. In such cases both parties benefit from time and cost savings. Some companies have used the Internet to improve their one-on-one relationships with customers. By providing more information in a more timely and efficient manner, a company enables customers to learn more about what it has to offer (Azoulay \& Kapferer, 2003). This increases the opportunity for cross-selling and customer retention. In a welldesigned integrated marketing communications program, the Internet and personal selling are designed to be complementary tools - working together to increase sales. It appears that more and more companies are coming to this realization.

\section{PUBLIC RELATIONS ON THE INTERNET}

The role of PR is to look after the nature and basis of the external relationships between the organization and all stakeholder groups. It is aimed at creating a sustainable corporate brand and an overall company image within the marketplace.

Publics, in the main, consist of:

- Customer groups

- Local and central government

- The general public

- Financial institutions - investors/shareholders/borrowers

- The media - TV, press, radio (locally and nationally)

- Opinion leaders/formers

- Internal marketplace - employees, trades unions, employee relations bodies, trade associations

- Potential employees.

Some of the more traditional public relations organizations do not use the Net at all, while most others use it primarily as a tool for disseminating information. The Web offers a number of opportunities to public relations practitioners, including (Hughes \& Fill, 2006):

(1) the development of media relations websites,

(2) the ability to provide customized information dissemination,

(3) the development of positive e-mail relationships.

\section{DIRECT MARKETING ON THE INTERNET}

Direct marketing - An interactive system of marketing which uses one or more advertising media to effect a measurable response at any location (Hughes \& Fill, 2006).

This is one of the most rapidly evolving and changing areas of marketing communications and promotional activities. Key driving forces of change relate to (Palmer, 2005):

- Changing dynamics in demographics and lifestyles

Increasing competition

- Customer power

Fragmentation of the media

Increasing costs of media

Emerging distribution channels

Changes in market information

New technologies
Direct Mail - Direct mail on the Internet (e-mail) is essentially an electronic version of regular mail. Like regular mail it is highly targeted, relies heavily on lists, and attempts to reach consumers with specific needs through targeted messages. As we discussed earlier under personalization, consumers can opt to have specific types of email sent to them and other types not sent (Hughes \& Fill, 2006).

Sometimes users may also receive less targeted and unwanted e-mails. The electronic equivalent of junk mail, these messages are referred to as SPAM. (One e-mail filtering company estimates that as many as 25 percent of all e-mails are SPAM.) (Belch \& Belch, 2003). Interestingly, unlike many other e-mail marketers, the company does not use SPAM. It sends messages only to those who have agreed to receive them - an indication that junk mailing may not be necessary to be successful. The company recently aired television commercials to promote the ease and efficiency of using its online catalog, and sent customers in its existing database direct-mail pieces informing them of the same. In turn, many e-marketing companies now send out print catalogs to promote their sites (Belch \& Belch, 2003).

\section{CONCLUSION}

The Internet has given us e-mail for use in contacting and keeping in touch with editors. It has given us newsgroups, where there can be a liberal exchange of ideas with others who have similar interests. The Internet has given us gads of information and the ability to choose what information is on a web site. It has given us search engines, which are capable of cataloging every word on web sites and directories, which list web sites and their pages. The Internet is shrinking the world. And lastly, it has made it possible for every person to research any subject as thoroughly as desired from his home or office. Thus, it has become an avenue for reaching potential consumers of products worldwide and is an important part of the marketing mix available to every company.

Overall, the Internet offers marketers some very definite advantages over traditional media. At the same time, disadvantages and limitations render this medium as less than a one-stop solution. However, as part of an integrated marketing communications program, the Internet is a very valuable tool

\section{REFERENCES}

Azoulay, A. \& Kapferer, J.-N. (2003). Do brand personality scales really measure brand personality? Journal of Brand Management, 11 (2), 143-55

Belch G.E. \& Belch M.A. (2003), Advertising and PromotionAn integrated marketing communications perspective, The Mc Grow - Hill Companies, ISBN 0-756-8010-5, USA

Fombrun, C., Gardberg, N. \& Sever, J. (2000). The Reputation Quotient ${ }^{\mathrm{TM}}$ : a multi-stakeholder measure of corporate reputation. Journal of Brand Management, 7 (4), 241-56

Hughes G.\&Fill Ch. (2006), The official CIM coursebook Marketing communication 2006-2008, Oxford, ISBN 9780-7506-8010-3, England

Milton, L. \& Westphal, J. (2005). Identity confirmation networks and cooperation in work groups. Academy of Management Journal, 48 (2), 191-212

Larkin, J. (2003). Strategic Reputation Risk Management. Basingstoke: Palgrave Macmillan

Palmer, A. (2005). Principles of Services Marketing. London: McGraw Hill. Parasuraman, A, Zeithaml, V. and Berry, L. (1988). SERVQUAL: a multipleitem scale for measuring consumer perceptions of service quality. Journal of Retailing, 64 (1), 12-40 